\title{
Investigasi Performa Turbin Angin Crossflow Dengan Simulasi Numerik 2D
}

\author{
Diniar Mungil Kurniawati ${ }^{*}$, Illa Rizianiza², Gad Gunawan ${ }^{3}$ \\ ${ }^{1,2,3}$ Program Studi Teknik Mesin, Institut Teknologi Kalimantan, Indonesia \\ *diniarmungil@lecturer.itk.ac.id
}

\begin{abstract}
Wind turbine is a solution to harness of renewable energy because it requires wind as the main energy. Wind turbine work by extracting wind energy into electrical energy. Crossflow wind turbine is one of the wind turbines that are developed because it does not need wind direction to produce maximum efficiency. Crossflow wind turbines work with the concept of multiple interactions, namely in the first interaction the wind hits the first level of turbine blades, then the interaction of the two winds, the remainder of the first interaction enters the second level blades before leaving the wind turbine. In the design of crossflow wind turbine the diameter ratio and slope angle are important factors that influence to determine of performance in crossflow wind turbine. In this study varied the angle of slope $90^{\circ}$ and variations in diameter ratio of 0.6 and 0.7. The study aimed to analyze the effect of diameter ratio and slope angle in performance of the crossflow wind turbine. This research was conducted with numerical simulation through $2 D$ CFD modeling. The results showed that the best performance of crossflow wind turbine occurred at diameter ratio variation 0.7 in TSR 0.3 with the best $C_{P}$ value 0.34 .
\end{abstract}

Keywords : Crossflow, Diameter ratio, Slope Angle

\begin{abstract}
Abstrak
Turbin angin merupakan sebuah solusi pemanfaatan energi terbarukan karena hanya membutuhkan angin sebagai energi utamanya. Turbin angin bekerja dengan mengekstraksi energi angin menjadi energi listrik. Turbin angin crossflow merupakan salah satu turbin angin yang dikembangkan karena tidak membutuhkan arah angin untuk menghasilkan efisiensi yang maksimal. Turbin angin crossflow bekerja dengan konsep interaksi ganda yaitu pada interaksi pertama angin menabrak sudu-sudu turbin tingkat pertama, kemudian interaksi kedua angin sisa interaksi pertama masuk ke sudu-sudu tingkat kedua sebelum meninggalkan turbin angin. Dalam perancangan turbin angin crossflow rasio diameter dan sudut kemiringan sudu menjadi faktor penting yang mempengaruhi penentu kinerja pada turbin angin crossflow. Pada penelitian ini memvariasikan sudut kemiringan sudu $90^{\circ}$ serta variasi rasio diameter sebesar 0.6 dan 0.7. Penelitian bertujuan untuk menganalisis pengaruh rasio diameter dan sudut kemiringan terhadap kecepatan putar dan daya yang dihasilkan sebagai parameter kinerja turbin angin crossflow. Penelitian ini dilakukan dengan simulasi numerik melalui pemodelan CFD 2D. Hasil penelitian menunjukkan bahwa peforma turbin angin terbaik rata-rata terjadi pada rasio diameter 0,7 pada TSR 0,3 dengan nilai $C_{\mathrm{P}}$ terbaik sebesar 0.34 .
\end{abstract}

Kata kunci : Crossflow, Rasio Diameter, Sudut Kemiringan Sudu

\section{Pendahuluan}

Listrik merupakan salah satu kebutuhan yang sangat diperlukan oleh masyarakat. Namun, saat ini Indonesia masih menggunakan pembangkit listrik yang menggunakan energi fosil. Oleh karena itu dibutuhkan pembangkit energi listrik yang menggunakan energi terbarukan, salah satu sumber energi terbarukan yang tersedia adalah angin. Turbin angin adalah suatu alat yang mengekstrak energi kinetik dari angin menjadi energi listrik. Daya yang dihasilkan turbin 
angin tidak begitu besar dibanding dengan pembangkit listrik lainnya, namun dengan daya yang dihasilkan oleh turbin angin mampu memberikan solusi dalam kebutuhan listrik penduduk sekitar dengan kapasitas yang kecil.

Turbin angin dibedakan menjadi 2 jenis yaitu Turbin Angin Sumbu Vertikal (TASV) dan Turbin Angin Sumbu Horizontal (TASH). Dalam penggunaannya kedua tipe turbin angin ini mempunyai beberapa kelebihan dan kekurangannya masing-masing serta konstruksi yang berbeda-beda. Kelebihan dari TASV yaitu, lebih sederhana karena tidak memerlukan mekanisme menguap atau pitch, semua komponen ditempatkan pada rumahan yang ada di tanah, membuat perawatan lebih mudah, dan turbin angin sumbu vertikal tidak mengubah sumbu rotasi sudu dalam mencari angin sehingga tidak menyebabkan hilangnya energi secara signifikan [1]. Kerugian utama dari beberapa TASV adalah bahwa biasanya TASV tidak memulai sendiri, diperlukan mekanisme tambahan untuk mendorong dan memulai turbin, setelah dihentikan. Ketika rotor menyelesaikan putarannya, sudu harus melewati zona mati aerodinamis yang akan menghasilkan penurunan efisiensi sistem. Ada kemungkinan bahwa sudu dapat beroperasi pada kecepatan tinggi yang berbahaya yang menyebabkan sistem gagal, jika tidak dikontrol dengan baik [2].

Turbin angin crossflow merupakan salah satu turbin angin sumbu vertikal yang memiliki banyak kelebihan. Turbin angin crossflow dapat dipasang pada daerah yang memiliki kecepatan angin yang rendah, sehingga sangan cocok dijadikan salah satu alternatif turbin angin yang ideal untuk potensi angin di Indonesia.Hal ini dikarenakan turbin angin crossflow memiliki kecepatan start up angin yang rendah dibandingkan dengan turbin angin sumbu vertikal lainnya. Dalam pemanfaatan turbin angin crossflow menjadi energi listrik dibutuhkan efisiensi kinerja yang baik.

Penentuan efisiensi kinerja dari sebuah turbin dibutuhkan parameter-parameter penentu yang bernilai baik seperti Tip Speed
Ratio (TSR), Koefisien Daya $\left(C_{P}\right)$, dan Koefisien Torsi $\left(C_{T}\right)$. Untuk kecepatan angin nominal yang tertentu, tip speed ratio akan berpengaruh pada kecepatan putar rotor. Tip speed ratio merupakan rasio kecepatan ujung motor terhadap kecepatan angin bebas [3].

Sebuah turbin tidak sepenuhnya dapat mengekstraksi kekuatan teoritis yang tersedia dalam aliran angin. Ketika aliran angin melewati turbin, sebagian energi kinetiknya ditransfer ke rotor dan udara yang meninggalkan turbin membawa sisanya. Adanya rasio daya aktual yang dikembangkan oleh rotor terhadap daya teoritis yang tersedia dalam angin akan membentuk efisiensi yang biasa disebut sebagai koefisien daya rotor $\left(C_{P}\right)$ [2]. Dalam kinerja suatu turbin angin, torsi menjadi salah satu aspek penting untuk mencapai performa yang baik, torsi teoritis maksimum yang didapat, dalam praktiknya poros rotor hanya dapat mengembangkan sebagian kecil dari batas maksimum ini. Rasio antara torsi aktual yang dikembangkan oleh rotor dan torsi teoritis disebut sebagai koefisien torsi $\left(C_{T}\right)[2]$.

\section{Metoda Penelitian}

Pada dasarnya CFD merupakan pendekatan dari karakteristik fluida dengan kondisi real. CFD menggunakan persamaan dasar dinamika fluida yaitu persamaan kekekalan massa dan momentum. Berikut persamaan dasar yang digunakan dalam simulasi turbin crossflow.

Berdasarkan hukum kekekalan massa maka hukum kontinuitas dapat dinyatakan sebagai berikut :

$$
\frac{\partial p}{\partial t}+u \frac{\partial p}{\partial t}+\rho a^{2} \frac{\partial u}{\partial x}=0
$$

Dalam simulasi turbin angin crossflow, kecepatan udara yang melewati turbin angin cenderung rendah. Sehingga fluida dapat diasumsikan sebagai fluida incompressible. Persamaan Navier-Stoke untuk fluida incompressible dapat ditulis sebagai berikut: 


$$
\begin{aligned}
& \rho\left(\frac{\partial u}{\partial t}+u \frac{\partial u}{\partial x}+v \frac{\partial u}{\partial y}=\rho g_{x}-\frac{\partial p}{\partial x}+\mu\left(\frac{\partial^{2} u}{\partial x^{2}}+\frac{\partial^{2} u}{\partial y^{2}}\right)\right. \\
& \rho\left(\frac{\partial v}{\partial t}+u \frac{\partial v}{\partial x}+v \frac{\partial v}{\partial y}=\rho g_{y}-\frac{\partial p}{\partial x}+\mu\left(\frac{\partial^{2} v}{\partial x^{2}}+\frac{\partial^{2} v}{\partial y^{2}}\right)\right.
\end{aligned}
$$

Perhitungan koefisien torsi $\left(\mathrm{C}_{\mathrm{T}}\right)$ dapat didefinisikan sesuai dengan persamaan berikut:

$$
C_{T}=\frac{T}{0.25 \rho v^{2} D S}
$$

Sedangkan koefisien daya dapat dinyatakan sebagai fungsi dari tip speed ratio dan $\mathrm{C}_{\mathrm{T}}$. adapun pesamaan dari $\mathrm{C}_{\mathrm{P}}$ sebagai berikut:

$$
C_{P}=\lambda C_{T}
$$

Dalam simulasi turbin angin sumbu vertikal crossflow dilakukan pada kecepatan angin $2 \mathrm{~m} / \mathrm{s}$ dengan variasi sudut kemiringan sudu dan rasio diameter. Pada simulasi juga dilakukan dengan menggunakan nilai TSR 0,1 hingga 0,4 , sehingga pada bagian rotating domain diaplikasikan mesh motion agar dapat memodelkan turbin dalam keadaan berputar dengan variasi kecepatan angular sebesar 0,4 $\mathrm{rad} / \mathrm{s} ; 0,8 \mathrm{rad} / \mathrm{s} ; 1,2 \mathrm{rad} / \mathrm{s} ; 1,6 \mathrm{rad} / \mathrm{s}$.

Pemodelan simulasi turbin angin juga dibutuhkan kondisi batas agar suatu fenomena nyata dapat direpresentasikan dengan akurat. Kondisi batas yang digunakan dalam simulasi dibagi menjadi 3 bagian yaitu pada bagian paling kiri fixed domain digunakan velocity inlet dimana pada bagian ini udara masuk melewati ruang tersebut dan kecepatan konstan $2 \mathrm{~m} / \mathrm{s}$ diasumsikan. Pada bagian paling kanan fixed domain digunakan pressure outlet dengan diaplikasikan relative static pressure $0 \mathrm{~Pa}$, dimana bagian ini merupakan tempat keluarnya udara dari ruangan tersebut. Pada bagian sisi atas dan sisi bawah dibuat boundary wall. Pengujian turbin dibuat dengan mengasumsikan bahwa kodisi dengan batas yang ideal.

Asumsi kondisi tersebut yang mempengaruhi aliran angin yang digunakan selama proses simulasi. Angin diasumsikan sebagai udara pada kondisi gas ideal dan steady state sehingga perhitungan persamaan dalam pemodelan akan lebih mudah dilakukan dan lebih mudah untuk dilakukan analisis.

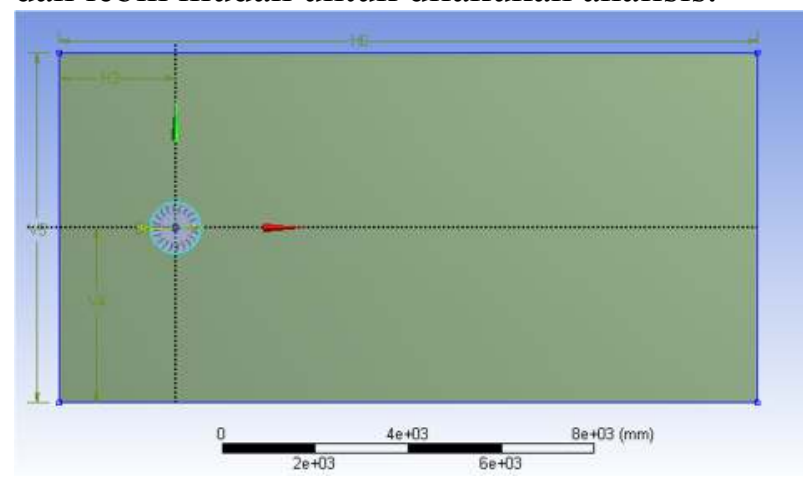

Gambar 1. Domain pengujian turbin

Aspek lain yang digunakan untuk memvalidasi model turbin angin sumbu vertikal crossflow adalah dengan menggunakan nilai skewness sebagai parameter kualitas meshing. Kualitas meshing sangat penting untuk dilakukan karena mempengaruhi hasil simulasi sehingga harus sampai pada kualitan minimal adalah good meshing. Penelitian dilakukan pada nilai skewness rata-rata 0,76 dirujuk pada kategori metode CFD sudah termasuk pada Good Meshing. Kategori tersebut mempunyai rentang nilai $0,5-0,8$ sebagaimana yang ditunjukkan oleh Gambar 2.

Skewness mesh metrics spectrum
\begin{tabular}{|c|c|c|c|c|c|}
\hline Excellent & Very good & Good & Acceptable & Bad & Unacceptable \\
\hline $0-0.25$ & $0.25-0.50$ & $0.50-0.80$ & $0.80-0.94$ & $0.95-0.97$ & $0.98-1.00$ \\
\hline
\end{tabular}

Gambar 2. Skewness mesh metrics spectrum

Pada pemodelan turbin angin crossflow digunakan metode triangular meshing. Adapun hasil meshing ditunjukkan pada Gambar 3 berikut.

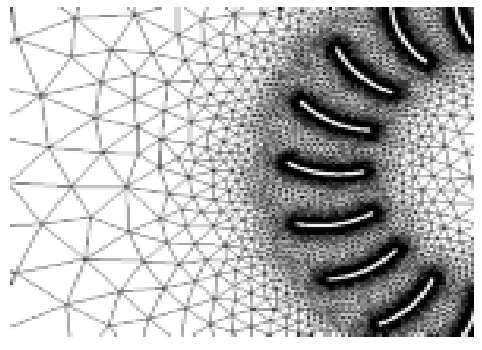

Gambar 3.Meshing pada turbin 


\section{Hasil Penelitian}

Power Coefficient atau $C_{P}$ adalah parameter tak berdimensi yang menunjukkan daya pada turbin angin di setiap TSR. Untuk mendapatkan nilai $C_{P}$ sendiri digunakan Persamaan 2.5 dimana TSR merupakan hasil bagi antara $C_{P}$ dan $C_{T}$, sehingga dilakukan perhitungan pada sampel turbin angin sumbu vertikal crossflow adapun hasil $C_{P}$ simulasi turbin angin sumbu vertikal crossflow didapatkan setelah dilakukan kalkulasi secara menyeluruh.

Turbin angin crossflow dengan 18 sudu mempunyai nilai $C p$ yang tinggi. Turbin angin dengan sudu yang lebih banyak meyebabkan turbin mencapai $C_{P}$ maksimalnya di TSR yang rendah [4]. Gambar 4.4 menunjukkan hubungan koefisien daya dengan tip speed ratio (TSR). Turbin dengan rasio diameter 0,7 dengan sudut kemiringan sudu $90^{\circ}$ pada TSR 0,3 menghasilkan nilai $C_{P}$ terbaik dengan nilai maksimum 0,35. Dari grafik yang dihasilkan bahwa nilai $C_{P}$ mengalami kenaikan dan dapat mencapai nilai puncak pada TSR tertentu, namun setelah itu nilai $C_{P}$ mengalami kecendrungan untuk turun [5].

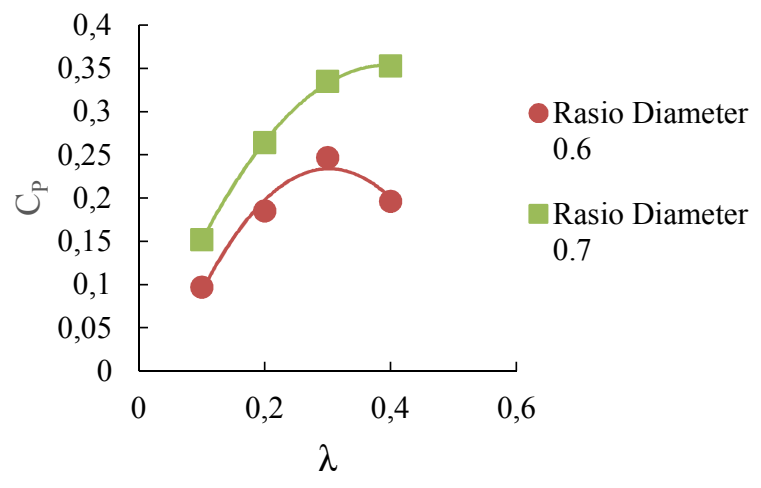

Gambar 4. Grafik hubungan antara $C_{P}$ dengan TSR

Berdasarkan grafik $C_{P}$ hasil simulasi diketahui bahwa $C_{P}$ akan meningkat seiring dengan bertambahnya TSR, namun $C_{P}$ akan mengalami penurunan setelah titik maksimal. Hasil yang diperoleh yaitu turbin yang mempunyai rasio diameter 0,6 dan 0,7 berturut-turut memiliki $C_{P}$ tertinggi yaitu 0,25 dan 0,35 pada TSR 0,4.
Kemiringan sudu $90^{\circ}$ merupakan tipe kemiringan sudu yang sering digunakan dalam pembuatan turbin angin crossflow. Hal tersebut dikarenakan pembuatan sudu turbin lebih mudah dilakukan. Sudu $90^{\circ}$ memiliki bukaan sudu yang tepat segari dengan garis sumbu turbin. Dengan demikian produksi angin yang dapat diekstrak menjadi energyikinetik oleh bilah-bilah turbin lebih besar daripada variasi kemiringan sudu yang lainnya.

Gambar 5 merupakan grafik hasil simulasi koefisien torsi terhadap kecepatan tip pada turbin. Hasil menunjukkan bahwa torsi cenderung mengalami penurunan nilai seiring dengan kenaikan kecepatan. Pada turbin yang mempunyai rasio diameter 0.6 memilki torsi awal yang lebih tinggi daripada turbin yang berrasio diameter 0.7. Hal tersebut menunjukkan bahwa turbin dengan rasio diameter 0.6 membutuhkan kecepatan angina yang lebih tinggi untuk dapat memutar turbin karena membutuhkan putaran yang lebih besar untuk dapat memutar turbin. Pada saat kenaikan kecepatan angina turbin dengan rasio diameter 0.6 menghasilkan torsi yang lebih rendah dibandingkan dengan turbin yang mempunyai diameter rasio 0.7 . hal tersebut menunjukkan bahwa dengan bertambahnya kecepatan angin, turbin mempunyai putaran yang lebih besar dibandingkan dengan turbin dengan variasi yang lain.

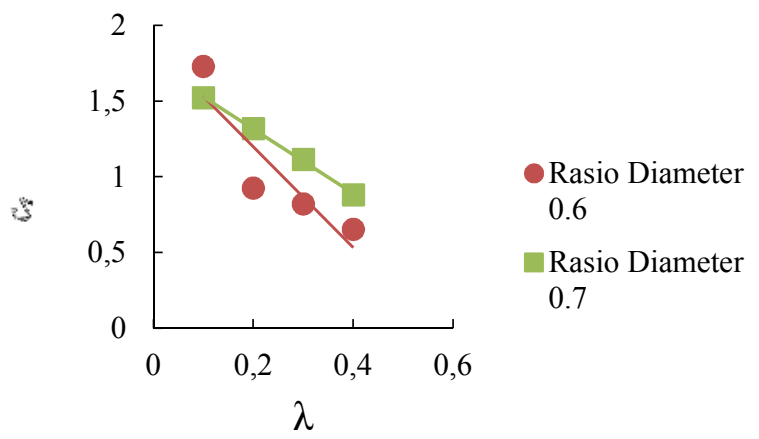

Gambar 5. Grafik hubungan $\mathrm{C}_{\mathrm{T}}$ dengan TSR

Jika dilihat dari hasil yang ditunjukkan oleh turbin dengan rasio diameter 0.7 , penurunan torsi lebih teratur daripada turbin yang memiliki diameter 0.6. Hal tersebut 
mengidentifikasi jika turbin lebih stabil berputar dengan seiringnya kenaikan kecepatan. Koefisien torsi didefinisikan sebagai perbandingan antara torsi actual yang dihasilkan oleh turbin dengan torsi teoritis yang dimiliki oleh turbin. Semakin besar nilai maka semakin besar perbandingannya. Koefisien torsi yang lebih rendah menunjukkan bahwa reduksi putaran turbin pada saat pengujian dengan torsi yang dihitung secara teoritis lebih kecil. Hal tersebut menunjukkan bahwa turbin mengekstraksi angin lebih baik. Akan tetapi, hasil pengujian yang didapatkan menyatakan bahwa turbin dengan diameter rasio 0.7 mempunyai putaran yang lebih stabil sehingga mempunyai nilai $C_{P}$ yang lebih besar dibandingkan dengan turbin yang memiliki rasio diameter 0.6.

Pemilihan rasio diameter dan sudut kemiringan sudu yang tepat sangat diperlukan untuk turbin angin dapat menghasilkan nilai koefisien daya yang terbaik. Rasio diameter dan sudut kemiringan sudu sangat berpengaruh pada nilai koefisien daya disebabkan oleh bentuk sudu yang berubah bentuk penampangnya sehingga dapat menyebabkan jumlah angin yang menabrak sudu turbin tidak dapat mengalir melewati penampang yang terlalu kecil maupun angin dapat terhambat pada penampang yang terlalu besar dan akan menyebabkan tekanan balik serta dapat menyebabkan jarak untuk transfer energi semakin besar dan meningkatkan turbulensi sehingga dapat menyebabkan turunnya koefisien daya pada turbin.

Pemilihan rasio diameter yang tepat merupakan salah satu aspek penting dalam menghasilkan koefisien daya yang maksimal. Nilai rasio diameter akan sangat berpengaruh pada nilai rim radial. Rim radial adalah selisih yang dihasilkan antara diameter luar dengan diameter dalam yang dibagi dua $\left(D_{1}-D_{2}\right) / 2$. Dalam pemilihan rim radial dibutuhkan nilai yang ideal. Hal itu disebabkan jika nilai rim radial terlalu besar maka jumlah angin yang menabrak sudu tidak akan optimal dikarenakan angin tidak dapat melewati penampang yang terlalu besar yang dapat mengakibatkan tekanan balik sehingga nilai koefisien daya akan kecil. Namun, jika lebar rim radial terlalu kecil akan melebarkan jarak transfer energi sehingga semakin besar dan meningkatkan turbulensi yang menyebabkan koefisien daya menurun [6].

Nilai $C_{P}$ pada diameter rasio 0,7 yang terlihat lebih besar dibandingkan dengan turbin berdiamter 0,6 bisa disebabkan oleh karena diameter rasio yang rendah akan mempengaruhi lebar rim radial dari turbin. Lebar rim radian menyebabkan interaksi negatif antara angina dengan sudu turbin [7]. Dengan meningkatkan rasio diameter diharapkan mampu mengurangi interaksi negatif tersebut dengan melihat bahwa meningkatkan rasio diameter dapat meningkatkan jarak transfer energi antara interaksi pertama dari angin ke turbin. Dengan demikian pada interaksi ke dua akan menerima kekurangan energi. Pada kondisi tersebut inner vortex akan membangun turbin bagian dalam dan hal tersebut isa dilakukan dengan menaikkan nilai rasio diameter.

\section{Kesimpulan}

Rasio diameter adalah salah satu parameter desain turbin angin crossflow yang mempunyai pengaruh pada besarnya koefisien daya yang dihasilkan oleh turbin. Hal tersebut berkaitan dengan peluang luasan yang dapat mengekra angin menjadi energi kinetik turbin angin. Semakin besar nilai rasio diameter akan menurunkan torsi negatif yang dihasilkan oleh turbin sehingga nilai koefisien daya pada turbin bisa meningkat. Torsi negatif adalah interaksi negatif antara putaran turbin dengan arah datang angin. Biasanya torsi negatef terjadi pada turbin yang berbasis gaya dorong seperti turbin angina crossflow.

\section{Saran}

Diperlukan adanya penelitian lebih lanjut mengenai parameter desain lain yang dapat mempengaruhi besarnya performa turbin angina seperi bentuk sudu, sudut kemirangan sudu dan rasio antara diameter dengan tinggi turbin untuk mendapatkan konfigurasi yang 
paling tepat sehingga dapat dijadikan rujukan sesuai dengan desain yang diperlukan dalam pengembangan dan pengaplikasian.

\section{Daftar Pustaka}

[1] Jain, Pramod. (2011), "Wind Energy Engineering”. McGraw Hill: Mc Graw.

[2] Mathew, S. (2006), "Wind Energy: Fundamentals, Resource Analysis, and Economics". Springer: New York.

[3] Barriyah, Kholifatul. (2016), “Uji Ekperimental Pengaruh Sudut Kemiringan Sudu, Radius Kemiringan Sudu dan Kecepatan Angin Pada Turbin Crossflow Terhadap Daya yang Dihasilkan Pada Sistem Pemulihan Energi yang Terintegrasi Dengan Menara Pendingin". Universitas Sebelas Maret: Surakarta.
[4] Castelli, Marco Raciti dkk. (2012), "Effect of Blade Number on a Straight-Bladed VerticalAxis Darrieus Wind Turbine". Journal of Aerospace and Mechanical Engineering Vol. 6 No. 1.

[5] Hau, E. (2005), "Wind Turbines: Fundamentals, Technologies, Application, Economics". Springer. Vol $2^{\text {nd }}$ Edition

[6] Mockmore, C. dan F. Merryfield, (1949), The Banki Water Turbine, Eng. Exp. Stn. Bull. Ser., vol. 25, no February, pp. 1-28. 